elegant paper offered "for debate." 6 It was lucid, but at a level of discussion at which many doctors will not feel at home; perhaps for this reason no debate followed. This letter is submitted as a contribution to that debate.

GEORge HEARN

Birmingham B13 8JZ

1 Egger J, Carter CM, Wilson J, et al. Is migraine
food allergy? A double-blind controlled trial of oligoantigenic diet treatment. Lancet 1983;ii: $36 \%-8$

2 Jon's VA, McLaughlan P, Shorthouse $M$, et al Food intolerance: a major factor in the pathogenesis of irritable bowel syndrome. Lancet 1982
ii:1115-7.

3 Jones VA, McLaughlan P, Shorthouse M, et al Food intolerance, prostaglandins, and irritable
bowel syndrome. I.ancet 1983;i:124. Rowe AH. Food allergy. Philadelphia: Lea and Febiger, 1932

5 Bray GW. Recent advances in allergy. London:

6 Dudley HAF. The controlled clinical trial and the advance of reliable knowledge: an outsider looks in Br Med f 1983;287:957-60.

\section{Clinical importance of enteric communication with abdominal abscesses}

SIR,-The paper by Dr S H Saverymuttu and others (5 January, $p$ 23) highlights the difficulty of diagnosing and localising intraabdominal abscesses and rightly emphasises the atypical clinical presentation and significant mortality associated with this condition. However, there is an assumption throughout that communication of an abscess with the bowel should be beneficial as it allows "drainage," whereas in fact most of these abscesses result from leakage of bowel content from the bowel, and the communication is the root of the problem.

Computed tomography, ultrasound scanning, and gallium scanning, as well as the indium-111 leucocyte scanning favoured by the authors, are all now available and their value in the localisation of abdominal sepsis has recently been investigated. Knochel et al achieved accurate localisation in $123 / 136$ patients by ultrasound, $116 / 126$ by ${ }^{111}$ In leucocyte scanning, and $77 / 80$ by computed tomography. ${ }^{1}$ All large series show false negatives and false positives, which in the case of ${ }^{111}$ In leucocyte scans may be due to uninfected haematomas and areas of inflammation without pus. Such patient with false positives are excluded by Dr Saverymuttu and others as only patients in whom the abnormality seen on the ${ }^{111}$ In scan was confirmed as an abscess by other means were included. Similarly, the statement that "overall"1' In scanning was more accurate than ultrasound" also seems unfair when the criteria for including a patient was that the abscess had to be detected on the ${ }^{111}$ In scan to begin with, thus also excluding false negative re sults. At present the various available scanning techniques have broadly similar diagnostic and localisation rates, but ultrasound is quicker and more readily available without the need to transpor an ill patient to a specialist centre for a procedure that may take 18 to 24 hours.

Intra-abdominal sepsis, especially when it occurs postoperatively, as it does in most cases, is a difficult problem, but I share the authors view that early drainage is desirable and am concerned at the modern tendency of "multiscanning," which tends to delay drainage procedures. Pitcher and Musher reported only one death among 29 patients in whom early drainage was achieved but 29 deaths from 48 in whom drainage was delayed. ${ }^{2}$ The demonstration of enteric communications using ${ }^{111}$ In leucocyte scans is of interest, but as the authors themselves state, these patients need surgical drainage of the abscess whether it communicates with the bowel or not.

Park Hospital,

P A SYKES

Knochel JQ, Koehler PR, Lee TG, Welch DM Diagnosis of abdominal abscess with computed tomography, ultrasound scan and "11 In leucocyte scans. Radiology 1980;137:425-32

Pitcher WD, Musher DM. Critical importance of early diagnosis and treatment of intra
Arch Surg 1982;117:328-33.

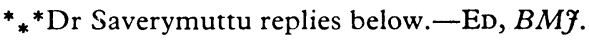

SIR,-Mr Sykes correctly emphasises the importance of early diagnosis to reduce the mortality of intra-abdominal abscesses. However, I do not believe that the routine ultrasound service available in most hospitals in Britain is adequate for this purpose.

Despite impressive results from specialist centres in the United States, reporting detection rates of $90 \%$ and greater,$^{13}$ there is no evidence that these figures can yet be matched in routine hospital practice either in the United States ${ }^{4}$ or here detection rates are $50 \%$ or less. ${ }^{56}$ An approach based solely on ultrasound is liable in many hospitals to miss a significant number of abdominal abscesses. The extent of this problem in the UK is unknown, and there is an urgent need for assessment. Although our study was not primarily aimed at assessing this problem it illustrates that it is of concern even in an academic institution, with $14 / 24$ abscesses in the series missed on ultrasound. This figure is an underestimate since it did not include the abscesses diagnosed only by computed tomography, laparotomy, and necropsy.

An "ideal" approach for abscess localisation has been recently proposed in which ${ }^{67} \mathrm{Ga}$ or ${ }^{111} \mathrm{In}$ leucocyte scintigraphy is used first in patients who are not critically ill or have no localising signs. Those with abnormal findings together with critically ill patients or those who have localising signs undergo ultrasound scanning or computed tomography. Those shown to have fluid collection then undergo percutaneous needle biopsy. ${ }^{7}$ Such a scheme is of unproved efficacy, but our series provides supportive evidence for the limited value of ultrasound in patients without localising signsin whom ${ }^{11}$ In leucocyte scanning should be the initial assessment. Quite clearly few centres in the UK have the resources to adopt this approach so an alternative is required. Since ultrasound alone is inadequate an additional diagnostic procedure is needed in patients with suspected abscesses. The choice is between additional imaging ("111 In leucocyte scanning or computed tomography) and early blind laparotomy. It is hard to judge whether the costs of providing rapid access to ${ }^{111}$ In leucocyte scanning/tomography for each district general hospital are justified to avoid the morbidity and mortality of a high unnecessary laparotomy rate. The arguments are complex since computed tomography and ${ }^{111}$ In leucocyte scanning have many clinical applications apart from abscess localisation. A cost benefit analysis based on a controlled trial of the management options is needed. My personal view is that a service for ${ }^{111}$ In leucocyte scanning is justified.

One final point which deserves emphasis is the rapid development in radiodiagnostic imaging. The conventional technique for saline ${ }^{11}$ In leucocyte labelling used by all comparative series for detecting sepsis in the United States ${ }^{9-11}$ has been superseded by plasma leucocyte labelling. ${ }^{12}$ The new technique avoids artefactal pulmonary leucocyte sequestration $^{13}$ and results in earlier detection of sepsis. ${ }^{14}$ Thus positive results can be routinely available on a four hour scan rather than the 18-24 hour scan with saline labelling.

S H SAVERymutTu London SW 17 ORE
1 Maklad NF, Doust BD, Bawm JE. Ultrasonic diagnosis of postoperative intraabdominal abscess. Radiology 1974;113:417-22

2 Korobkin M, Callen PW, Filley RA, et al. Comparison of computer tomography, ultrasonography and gallium-67 scanning in the evaluation of suspected gallium-67 scanning in the evaluation of suspected
abdominal abscess. Radiology 1978;129:89-93.

3 Taylor KJW, Wasson JF, Graaf D, Rosenfeld A Andriole VT. Accuracy of grey scale ultrasound diagnosis of abdominal and pelvic abscesses in 220 patients. Lancet 1978; : $: 83-4$. p Clayman CB. Images and reflections. [Editorial.]
fAMA 1981;246:2727.

5 Pitcher WD, Musher DM. Critical importance of early diagnosis and treatment of intraabdomina infection. Arch Surg 1982;117:328-33.

Sonnenwirth-Ozar E, Pollak EW. Diagnosis of postoperative in

7 Ferrucci JT, van Sonnenberg E. Intraabdominal abscess -radiological diag

8 Mueller PR, Simeone JF. Intraabdominal abscessdiagnosis by sonography and computer tomography. Radiol Clin North Am 1983;21:425-43.

9 Carroll B, Silverman PM, Goodwin DA, McDougal JR. Ultrasonography and indium-111-white blood scanning for detection of intraabdominal abscesses. Radiology 1981;140:155-60.

10 Knochel JQ, Koehler PR, Lee TG, et al. Diagnosis of abdominal abscesses with computer tomography ultrasound and 111 Indium leucocyte scans.
Radiology 1980;137:425-32. Radiology 1980;137:425-32.
Ascher NL, Forstrom L, Simmons RL. Radiolabeled autologous leukocyte scanning in abscess detection. World f Surg 1980;4:395-402.

12 Danpure HJ, Osman SO, Brady F. The labelling of blood cells in plasma with 111-In tropoplanate.
Br 7 Radiol 1982;55:247-9.

13 Saverymuttu SH, Peters AM, Reavy HJ, Danpure HJ, Osman SO, Lavender JP. Lung transit of labelling technique. Scand $\mathcal{f}$ Haematol $1983 ; 30$ $151-60$.

14 Peters AM, Saverymuttu SH, Reavy HJ, Danpure HJ, Osman SO, Lavender JP. Imaging inflammation with indium-111-tropolonate
leucocytes. F Nucl Med 1983;24:39-44.

\section{Infection with parvovirus during pregnancy}

SIR,-We read with interest the report by Dr E P Wright and colleagues (19 January, p 241) describing human parvovirus infection in pregnancy with subsequent birth of a healthy baby and endorse their recommendation that further cases should be investigated virologically. During the 1983-4 outbreak of erythema infectiosum associated with human parvovirus in Grampian ${ }^{1}$ we identified four similar episodes of serologically confirmed infection in pregnancy which were followed by normal deliveries.

Case 1-A 32 year old woman, 8-10 weeks pregnant, developed a rash which lasted two days. Her two young daughters had experienced a mild, erythematous illness one to two weeks previously.

Case 2-A 29 year old woman presented at 20 weeks' gestation with a severe, itchy rash on hands and feet. The rash lasted six days; there was no history of contact.

Case 3-The young son of a 33 year old woman developed serologically proved erythema infectiosum. The mother, who was then 23 weeks pregnant, remained clinically well.

Case 4-At 25 weeks' gestation a 27 year old woman developed a fleeting, scarlatiniform rash one day after onset of a rubella like illness in her young child.

Recent infection with human parvovirus was confirmed by significant serum concentrations of virus specific IgM and IgG antibodies. All four patients subsequently gave birth to healthy babies, although one boy (case 4 ) had a small penile cyst of doubtful importance. The babies' serum antibody concentrations did not indicate intrauterine infection; virus specific $\operatorname{IgM}$ antibody was not detected and the IgG concentrations generally reflected those of the mother at the time of birth.

We thank Dr G E D Urquhart, Virus Laboratory, Ninewells Hospital, Dundee, for help with one of our cases and Drs P P Mortimer and B Cohen, Virus Reference Laboratory, Colindale, for the serological investigations.

Reports of normal births despite serologically confirmed maternal infection with 